\title{
ANTIBIOTIC SB22484: A NOVEL COMPLEX OF THE AURODOX GROUP II. STRUCTURE ELUCIDATION OF THE FOUR FACTORS
}

\author{
Pietro Ferrari, Duncan Edwards ${ }^{\dagger}$, Gian Gualberto Gallo \\ and ENRICO SElva
}

MDRI - Lepetit Research Center, Via R. Lepetit 34-21040 Gerenzano, Italy

(Received for publication February 13, 1990)

\begin{abstract}
SB22484, active against Neisseriae gonorrhoeae and Neisseriae meningitidis, is a complex of four factors, designated 1 through 4, which from two pairs of isomers, 1 and 3 , and 2 and 4 . Factors 1 and 3 account for $65 \%$ of the complex, factor 3 being the predominant one.

On the basis of the existing and implemented correlations between structure and physico-chemical characteristics (UV and IR spectroscopies, ionization properties, MS as FAB and as negative and positive $\mathrm{CI},{ }^{1} \mathrm{H}$ NMR spectroscopy as $2 \mathrm{D}$ COSY and NOESY) in the aurodox field, the complete structures were assigned. Factor 3 can be described as $N-[7-[5(R)$ - $[7-[1,2$-dihydro-4-hydroxy- $1 H-2-$ oxo-3-pyridinyl]-6-methyl-7-oxo-1 $(E), 3(E), 5(E)$-heptatrienyl]tetrahydro-3( $S), 4(R)$-dihydroxyfuran2(S)-yl]-6(S)-methoxy-5,7(R)-dimethyl-2(E),4(E)-heptadienyl]- $\alpha(S)$-methyl-5(S)-methyltetrahydro$2(S), 4(S$ or $R)$-dihydroxy-6(S)-[1(E),3(Z)-pentadienyl]-2H-pyran-2-acetamide. Factor 1 is an epimer of factor 3 with the opposite configuration at the anomeric center. Factors 2 and 4 have an ethyl group instead of the methyl group $\alpha$ to the acetamide moiety and are in the same stereochemical relationship as the pair 1 and 3 .
\end{abstract}

SB22484 is a new antibiotic complex isolated from Streptomyces strain NRRL 15496 and is active against Neisseriae gonorrhoeae and Neisseriae meningitidis ${ }^{1}$. As the investigation carried out for novelty determination indicated that SB22484 belongs to the aurodox type antibiotics, antibiotic activity is suspected to involve inhibition of bacterial protein synthesis via interference with the elongation factor $\mathrm{Tu}(\mathrm{EF}-\mathrm{Tu})^{2,3)}$ and they are also referred to as "elfamycins"4).

SB22484 was shown by chromatographic analysis (see Fig. 1) to be a complex of four factors, designated 1, 2, 3, and 4 according to their chromatographic elution order in a reverse phase system $^{1)}$. These factors form two pairs of isomers ( 1 and 3, and 2 and 4 ) and the pair 1 and 3 account for about $65 \%$ of the complex. Furthermore, the two isomers of each pair are in chemical equilibrium in aqueous solution ${ }^{1)}$.

This paper deals with the structure elucidation of the four factors of SB22484.

Fig. 1. HPLC chromatogram of SB22484 complex.

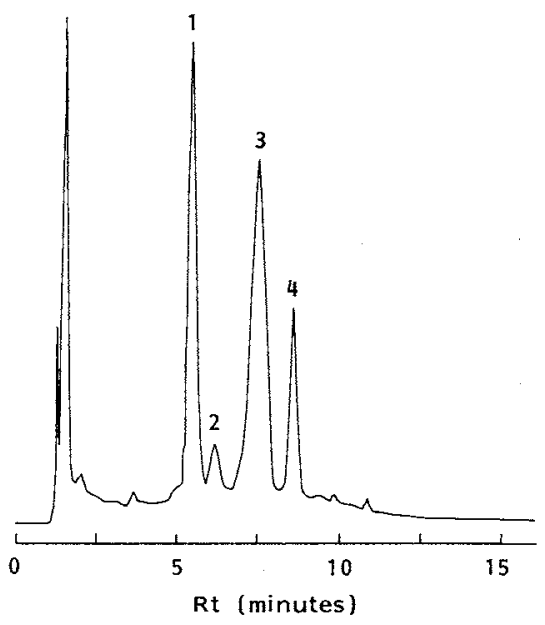

Column: Bakerbond $\mathrm{C} 8,0.46 \times 25 \mathrm{~cm}$. Mobile phases: A) $\mathrm{CH}_{3} \mathrm{CN}$ - THF - HCOONH ${ }_{4}(40: 40: 20)$.B) $\mathrm{CH}_{3} \mathrm{CN}-\mathrm{THF}-\mathrm{HCOONH}_{4}$ (10: 10:80). Gradient: linear from $10 \%$ of $\mathrm{A}$ to $90 \%$ of $\mathrm{A}$ in 20 minutes. Flow rate: $1.8 \mathrm{ml} /$ minute. Injection: $20 \mu \mathrm{l}$ of a solution in $\mathrm{CH}_{3} \mathrm{CN}-\mathrm{Na}_{2} \mathrm{CO}_{3} 0.1 \mathrm{M}(1: 9)$ at $5 \mathrm{mg} / \mathrm{ml}$.

$\dagger$ Present address: Farmitalia Carlo Erba Research Labs., Via C. Imbonati 24, 20159 Milano, Italy. 


\section{Experimental}

The UV spectra were recorded with a Perkin-Elmer spectrophotometer model 320 from water solutions at different $\mathrm{pH}$ values, obtained by adding various quantities of $\mathrm{HCl}$ or $\mathrm{NaOH}$ to the mother solution. Buffer solutions were not used, in order to make the far UV region sufficiently transparent.

The IR spectrum was obtained from a mineral oil suspension with a Perkin-Elmer spectrophotometer model 580 .

The acid-base analysis in aqueous medium was obtained by titrating with $0.1 \mathrm{~N} \mathrm{KOH}$ a solution of SB22484 in methylcellosolve - water $(4: 1$ and $1: 1)$.

The liquid chromatography (LC)-MS analysis was carried by direct liquid introduction (DLI) negative ion technique with a Hewlett-Packard instrument model 5958B on the antibiotic complex.

${ }^{1} \mathrm{H}$ NMR spectra were recorded in DMSO- $d_{6}$ and in acetone- $d_{6}$ solutions at $22^{\circ} \mathrm{C}$ on a Bruker AM-250 or on a Bruker AM-500 spectrometer, both equipped with an Aspect 3000 computer. The $2 \mathrm{D}$ experiments were: ${ }^{1} \mathrm{H}^{-1} \mathrm{H}$ correlation through 3 and 4 bonds in the phase sensitive mode double quantum filter (COSYPHDQ), using time-proportional-phase-incrementation in $\mathrm{f}_{1}$ and dipolar correlation through space by NOE in the phase sensitive mode (NOESYPH), using time-proportional-phase-incrementation in $f_{1}$. The mixing time was chosen as 200 minutes.

\section{Structure Determination}

The structure elucidations were carried out in analogy with the existing correlations between structure and physico-chemical characteristics of related antibiotics. The complete structures of the four factors of

Fig. 2. Structure and configuration of the four factors of SB 22484.

Numbering system from ref 5 .

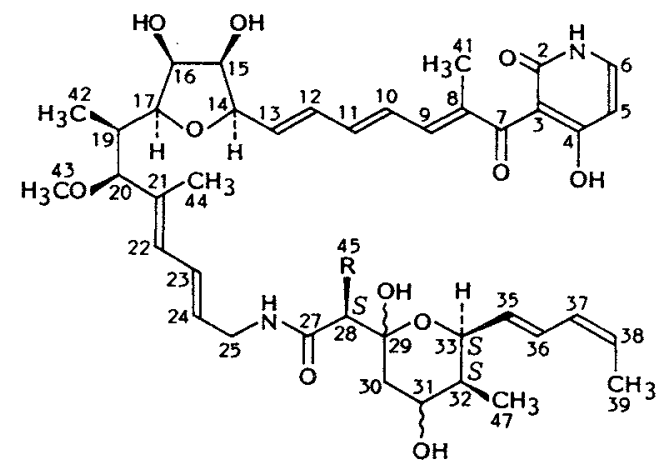

\begin{tabular}{|c|c|c|c|}
\hline Factor & MW & $\mathrm{R}$ & $29-\mathrm{OH}$ \\
\hline 1 & 752 & $\left.\mathrm{CH}_{3}\right\}$ & \multirow{2}{*}{$\beta, R$} \\
\hline 2 & 766 & $\left.\mathrm{C}_{2} \mathrm{H}_{5}\right\}$ & \\
\hline 3 & 752 & $\mathrm{CH}_{3}$ & \multirow{2}{*}{$\alpha, S$} \\
\hline 4 & 766 & $\left.\mathrm{C}_{2} \mathrm{H}_{5}\right\}$ & \\
\hline
\end{tabular}
the SB22484 complex (including the configurations) are shown in Fig. 2 together with the numbering system adopted by the authors of the paper on aurodox ${ }^{5}$. The majority of this investigation was carried out on isomers 1 and 3 .

Fig. 3. UV spectrum of SB22484 complex in water solution at different $\mathrm{pH}$ values.

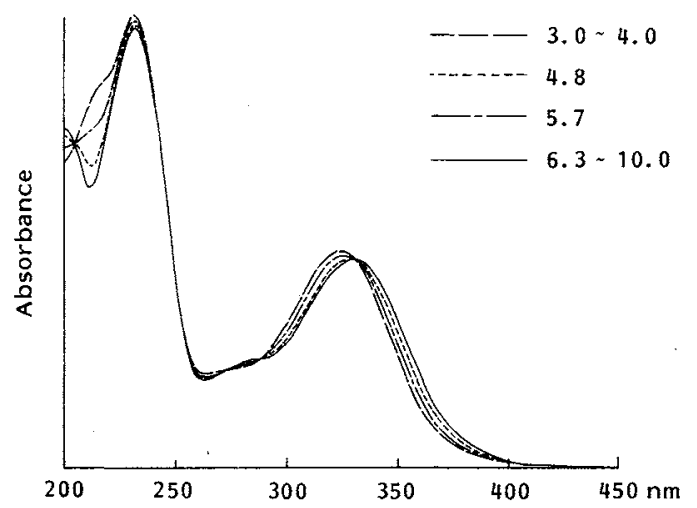

Table 1. UV bands and absorptivities of SB22484 in water solutions at different pH values.

\begin{tabular}{lcccccccc}
\hline pH value & $\begin{array}{c}\lambda_{\max } \\
(\mathrm{nm})\end{array}$ & $\mathrm{a}$ & $\begin{array}{c}\lambda_{\max } \\
(\mathrm{nm})\end{array}$ & $\mathrm{a}$ & $\begin{array}{c}\lambda_{\max } \\
(\mathrm{nm})\end{array}$ & $\mathrm{a}$ & $\begin{array}{c}\lambda_{\max } \\
(\mathrm{nm})\end{array}$ & $\mathrm{a}$ \\
\hline $3.0 \sim 4.0$ & 332 & 33.0 & $285(\mathrm{sh})$ & 17.0 & 232 & 68.6 & $200(\mathrm{sh})$ & 52.9 \\
4.8 & 330 & 32.6 & $285(\mathrm{sh})$ & 16.6 & 232 & 69.5 & $200(\mathrm{sh})$ & 51.6 \\
5.7 & 327 & 33.6 & $275(\mathrm{sh})$ & 15.7 & 232 & 70.4 & $200(\mathrm{sh})$ & 49.4 \\
$6.3 \sim 10.0$ & 325 & 34.1 & $270(\mathrm{sh})$ & 15.3 & 232 & 71.2 & $200(\mathrm{sh})$ & 47.2 \\
\hline
\end{tabular}

a: $1 \mathrm{~cm}, 1 \mathrm{~g} /$ liter. 


\section{UV Spectra}

The spectra in the relevant $\mathrm{pH}$ range are shown in Fig. 3. It must be mentioned that in acidic (below pH 3) and basic (above pH 12) media clear signs of decomposition were observed during the UV experiment. The bands and the absorptivities are given in Table 1.

The presence of an ionizable function connected to the chromophore is clearly deduced by inspection of the figure. In fact, the presence of five isosbestic points $(332,288,272,248$, and $206 \mathrm{~nm})$ indicate the existence of an acid-base equilibrium. By calculation from the different absorptions as a function of $\mathrm{pH}$, an apparent $\mathrm{p} K_{\mathrm{a}}$ of 5.4 was obtained for this ionizable function.

On the basis of the existing correlations between the UV absorption and structure in general ${ }^{6}$ and specifically for this class of antibiotics ${ }^{7)}$, the following assignments can be made. The maxima that are sensitive to the $\mathrm{pH}$, at $332 \mathrm{~nm}, \varepsilon_{\mathrm{mol}}=24,820\left(325 \mathrm{~nm}, \varepsilon_{\mathrm{mol}}=25,640\right)$ and $200 \mathrm{~nm}, \varepsilon_{\mathrm{mol}}=39,780(215 \mathrm{~nm}$, $\varepsilon_{\mathrm{mol}}=44,550$ ) are due to the extended chromophore formed by the trienone and 4 -hydroxy- $\alpha$-pyridone, while the maximum not sensitive to the $\mathrm{pH}$ at $232 \mathrm{~nm}, \varepsilon_{\mathrm{mol}}=51,590$, is due to the two separate diene chromophores. Furthermore, the blue shift displayed by the $332 \mathrm{~nm}$ band by increasing the $\mathrm{pH}$ is a behavior unexpected for a phenol but can be interpreted as due to the presence of the ionizable $\mathrm{OH}$ group on the $\alpha$-pyridone ring ${ }^{8)}$.

\section{IR Spectrum}

The main bands of the IR spectrum (see Fig. 4) are summarized in Table 2, together with the relevant assignments. Table 2 shows that the spectrum is in agreement with an aurodox structure, considering the presence of an $\alpha$-pyridone, a secondary trans amide, polyenic systems, and a hemiketalic pyran ring.

\section{Ionization Studies}

A function with a $\mathrm{p} K_{\mathrm{MCS}}=8.2$ was revealed. The same titration carried out in methylcellosolve - water (1:1) showed a $\mathrm{p} K_{\mathrm{MCS}}$ value of 7.2 , in agreement with the behaviour of an acid. This function can be correlated to the $\mathrm{p} K_{\mathrm{a}}=5.4$ obtained from the UV spectra and assigned to the 4 -hydroxy- $\alpha$-pyridone moiety.

The ionization in non-aqueous medium was obtained from a solution of SB22484 in glacial acetic acid titrated with $\mathrm{HClO}_{4}$ with the aim of getting information on weakly basic functions. The presence of a very weakly basic function was found, which is attributable to the pyridone nitrogen ${ }^{8}$.

Table 2. Attributions of the main functional IR absorption bands in mineral oil suspension.

\begin{tabular}{ll}
\hline \multicolumn{1}{c}{$v\left(\mathrm{~cm}^{-1}\right)$} & \multicolumn{1}{c}{ Assignment } \\
\hline $3700 \sim 3100$ & $v_{\mathrm{OH}}, v_{\mathrm{NH}}$ \\
1690 & $\alpha$-Pyridone $v_{\mathrm{C}=\mathrm{O}}$ \\
1640 & Amide I $\left(v_{\mathrm{C}=\mathrm{O}}\right)$ \\
1640,1610 & $v_{\mathrm{C}=\mathrm{C}}$ \\
$1570 \sim 1530$ & Heterocyclic $v_{\mathrm{C}=\mathrm{C}}$ and amide II $\left(\delta_{\mathrm{NH}}\right)$ \\
$1170 \sim 950$ & Sugar $v_{\mathrm{C}-\mathrm{o}}$ \\
808 & Pyridone $\gamma_{\mathrm{CH}}$ \\
\hline
\end{tabular}

Fig. 4. IR spectrum of SB22484 factor 3 in mineral oil suspension.

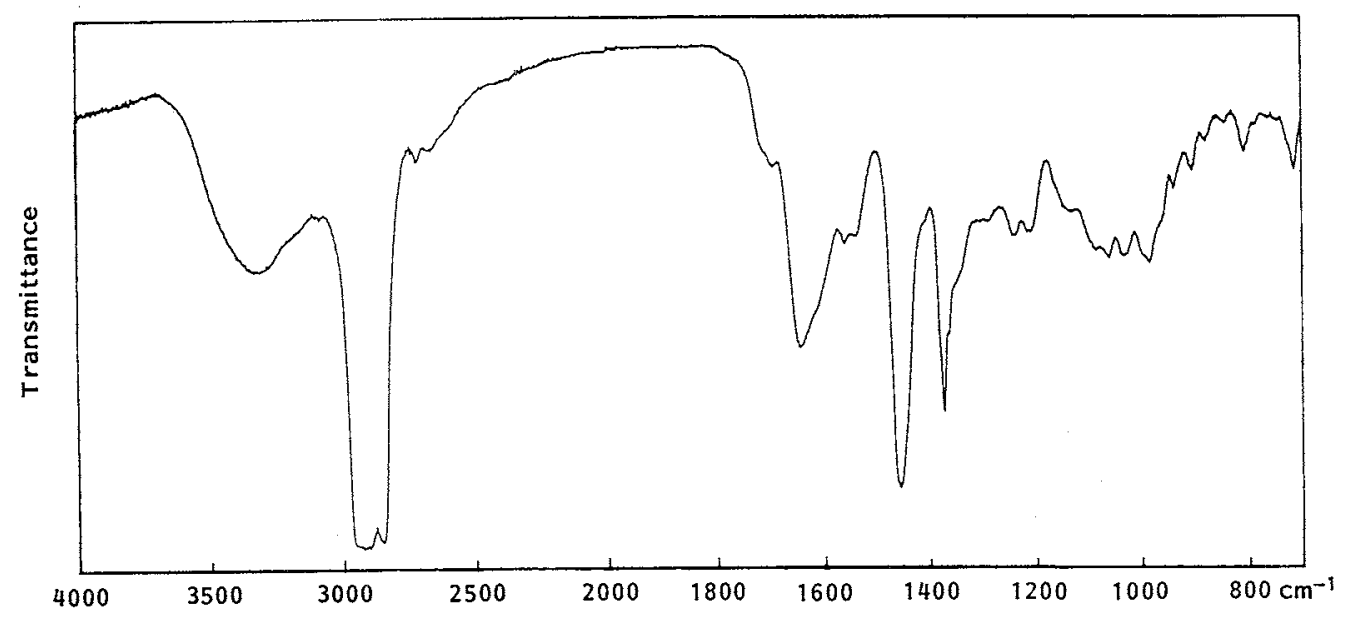


Fig. 5. DLI negative ion spectra of SB22484.

(A) Factor 3, (B) factor 4.
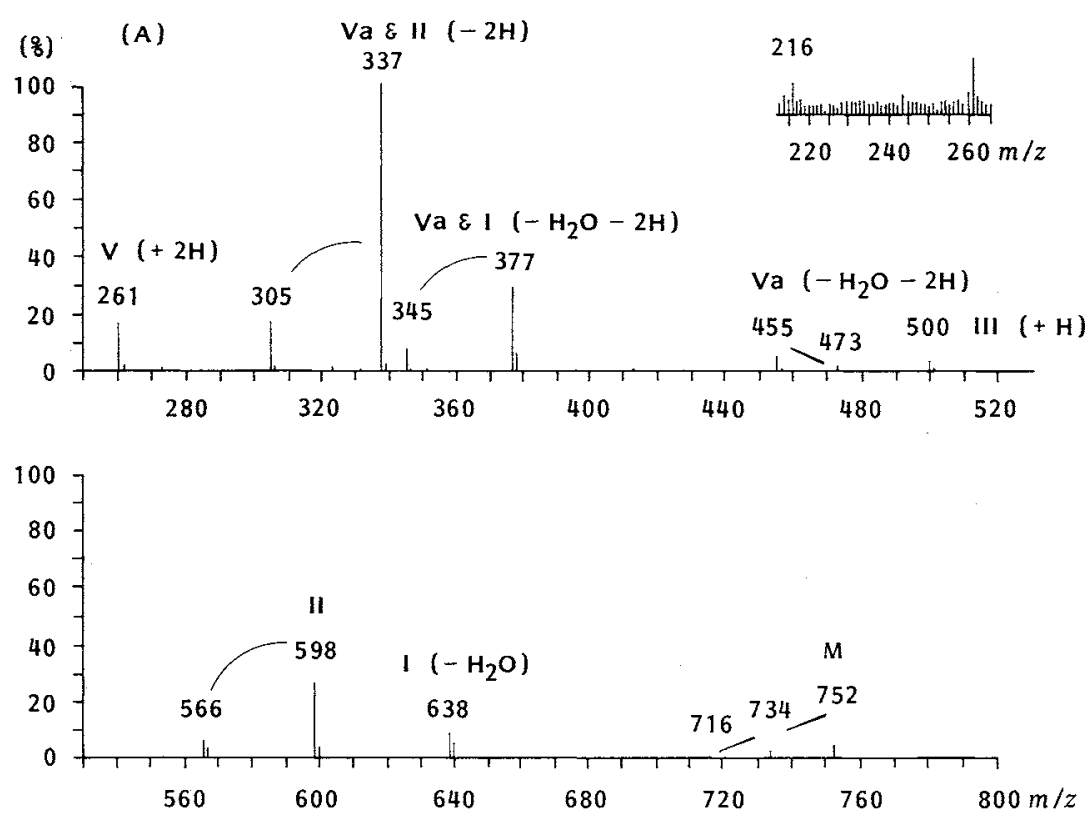

(B)

$$
\text { Va } \& \|(-2 \mathrm{H})
$$
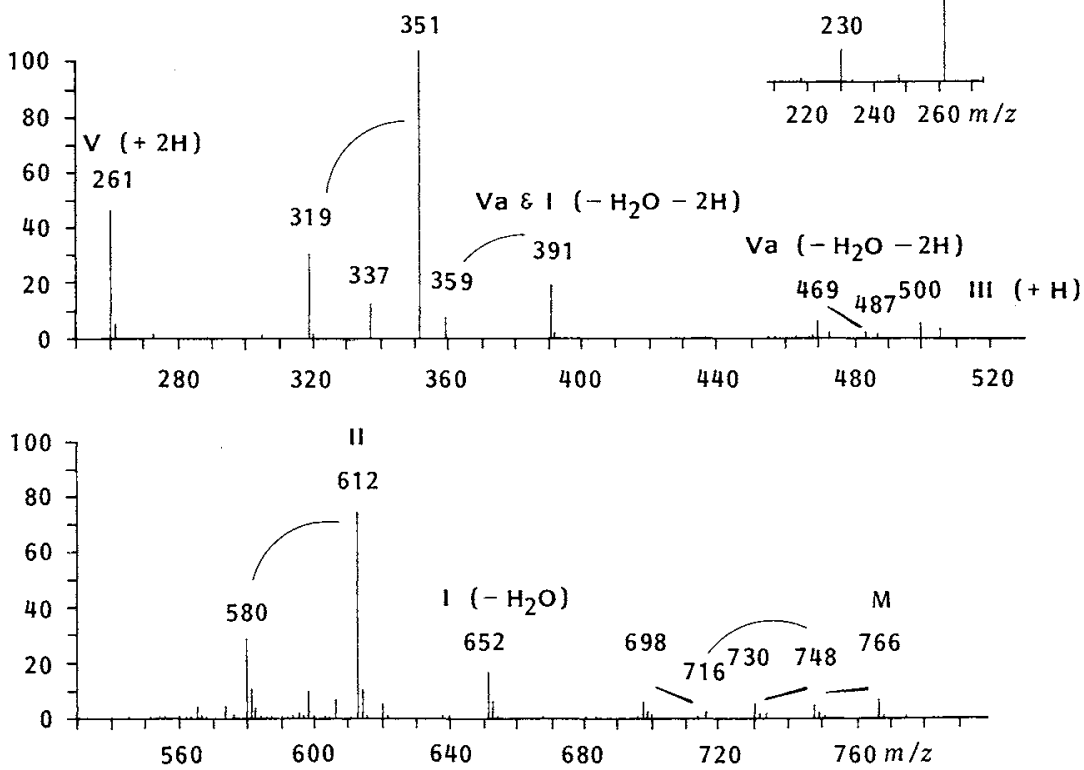

The skeletal fragmentations are indicated by roman numerals. Wedge-shaped arrows indicate water losses, and curved lines indicate methanol losses.

MS Studies

DLI negative ion LC-MS analysis was originally carried out on the antibiotic complex ${ }^{9)}$. The four components were chromatographically resolved and the corresponding mass spectra showed identical $\mathrm{m} / \mathrm{z}$ values for components 1 and 3 , and likewise for the pair 2 and 4 , strongly suggesting that SB22484 is composed of two pairs of isomers. In a subsequent MS study, involving both FAB and DLI 
ionization, the isolated components 3 and 4 were compared with other aurodox type antibiotics ${ }^{9}$. The MW's of components 3 and 4 were shown to be 752 and 766, respectively, by the observation of $\mathrm{M}^{-}$at these values in the DLI negative ion spectra (see Fig. 5). Correspondingly, in the FAB negative ion spectra obtained in thioglycerol matrix, the $(\mathrm{M}-\mathrm{H})^{-}$peaks are at $m / z 751$ and 765 and the $(\mathrm{M}-\mathrm{H}+\text { thioglycerol })^{-}$ peaks are at $m / z 859$ and 873 .

The DLI negative ion spectra are qualitatively similar to those of other aurodox type molecules containing a 2,3-dihydroxytetrahydro-furan ring ${ }^{9}$. The fragmentation pattern observed was very diagnostic and was interpreted as shown in Figs. 5 and 6 . After the expected losses of water and methanol, the peaks denoted as I $\left(-\mathrm{H}_{2} \mathrm{O}\right)(638$ for 3 or 652 for 4), II (598 for 3 or 612 for 4), III $(+\mathrm{H})(500$ for 3 and 4$)$, Va $\left(-\mathrm{H}_{2} \mathrm{O}-\mathrm{H}_{2}\right)$ (473 for 3 or 487 for 4$), \mathrm{V}\left(+\mathrm{H}_{2}\right)(261$ for 3 and 4$)$, Va and $\mathrm{I}\left(-\mathrm{H}_{2} \mathrm{O}-\mathrm{H}_{2}\right)(377$ for 3 or 391 for 4$)$, and $\mathrm{Va}$ and II $\left(-\mathrm{H}_{2}\right)$ (337 for 3 or 351 for 4) indicate that, in a comparison with aurodox, the pyran moiety in SB22484 is deoxygenated at position 3 and desmethylated at position 5 and that the 14 mass unit difference between the pairs 1 and 3 , and likewise 2 and 4 is located at position 28 .

\section{NMR Spectra}

The ${ }^{1} \mathrm{H}$ NMR spectrum of SB22484 factor 3 is shown in Fig. 7. Examination of this spectrum for the assignment of the signals and their attribution to the aurodox type structure, including configurations was accomplished by a number of $2 \mathrm{D}$ experiments, e.g., the COSYPHDQ is shown in Fig. 8.

The attribution of all the signals to the relevant protons is reported in Table 3 for factors 1 and 3, in comparison with the data for phenelfamycin $\mathrm{A}^{10 \text { ) }}$ and kirromycin ${ }^{11}$. The structures and configurations of SB22484 are substantially the same as that of kirromycin. The only important difference is located at position 32, where one of the two methyl

Fig. 6. Interpretation of the fragmentation of SB22484 factor 3 from the DLI negative ion spectrum.

The fragments, indicated by roman numerals, are characterized by their $m / z$ values.

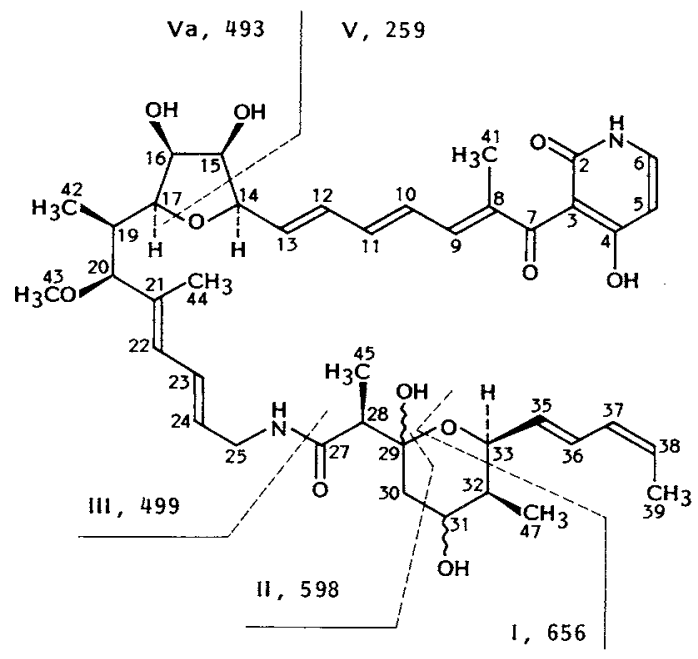

Fig. 7. ${ }^{1} \mathrm{H}$ NMR spectrum of SB22484 factor 3 in DMSO- $d_{6}$ solution at $250 \mathrm{MHz}$.

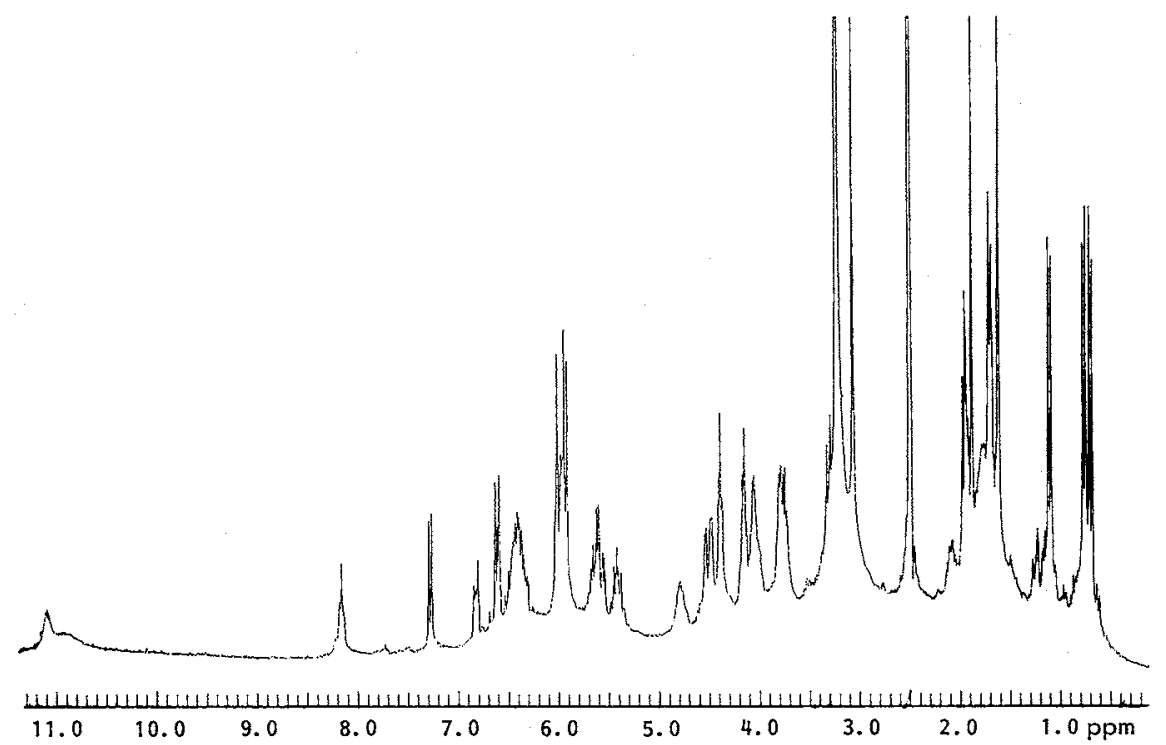


Fig. 8. ${ }^{1} \mathrm{H}^{-1} \mathrm{H}$ COSYPHDQ spectrum of SB22484 factor 3 in DMSO- $d_{6}$ solution at $250 \mathrm{MHz}$.

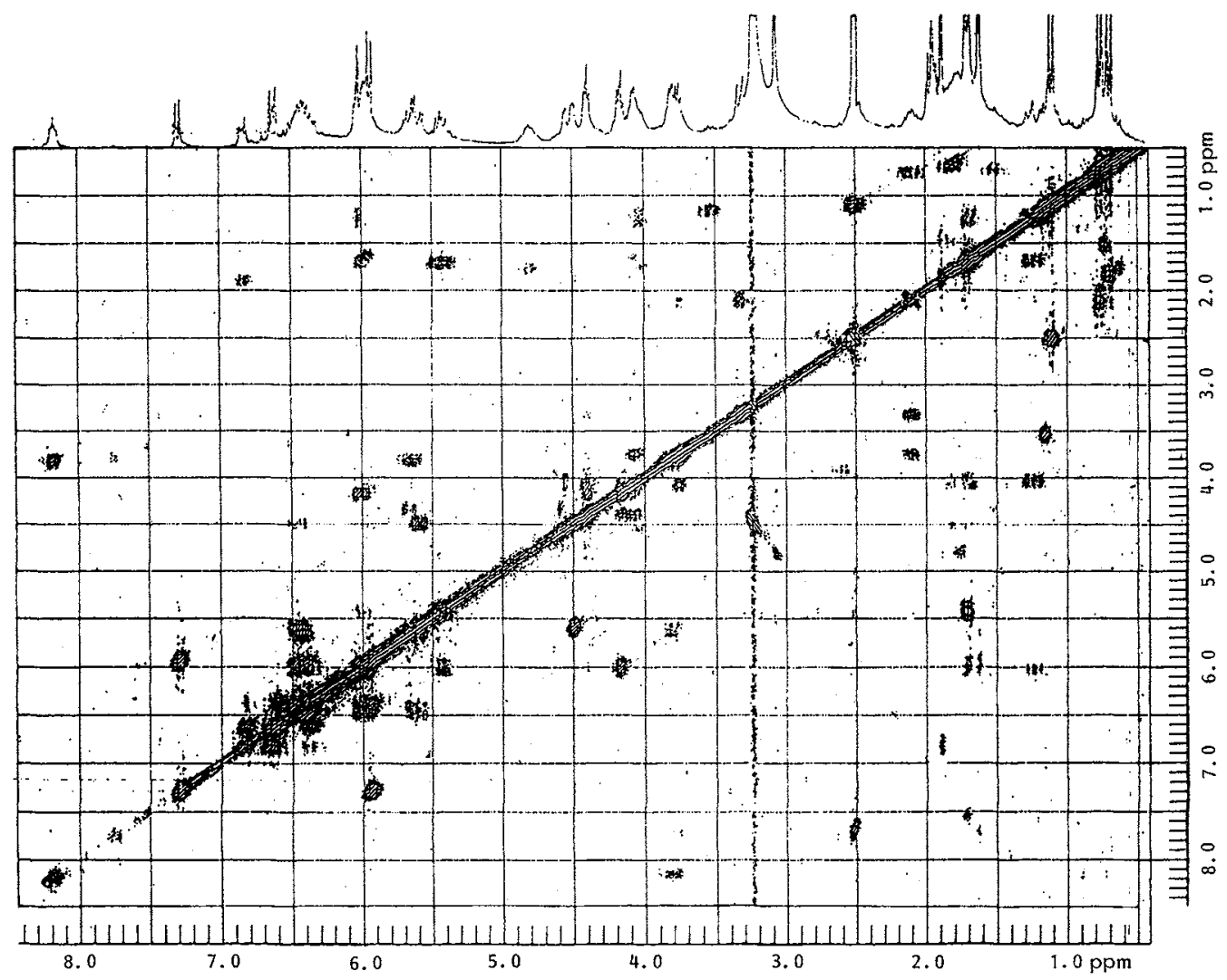

groups present in kirromycin-like molecules is lacking in SB22484, thus generating an additional stereocenter. The configuration of this new stereogenic center $\mathrm{C}-32$ could be assigned from the NOESYPH experiment, as indicated by the proximities shown for isomer 3 in Table 4 . Starting from the configuration $S$ of C-33, assigned by comparison with kirromycin and other kirromycin-like molecules the diaxial proximities of $47-\mathrm{CH}_{3}$ to one of the two $30-\mathrm{H}$ and of $29-\mathrm{OH}$ to $33-\mathrm{H}$ indicate for factor 3 the configuration $S$ for C-32 and $S(\alpha)$ for C-29. On the other hand, the configuration of the C-31 center might be assigned as $S$ by analogy with kirromycin, but this configuration is not warranted by the present NOESYPH experiment and it remains uncertain. In fact, the configuration of this center is not unique in aurodox type molecules, e.g., the antibiotics $\mathrm{A} 73 \mathrm{~A}^{12)}$ and $\mathrm{A} 40 \mathrm{~A}$ (factumycin) ${ }^{13)}$ are $R$ and $S$ epimers, respectively, at $\mathrm{C}-31$.

The assignment of the structure to the isomeric factors 1 and 3 was based on the differences between the NMR signals $26-\mathrm{NH}, 45-\mathrm{CH}_{3}$ and $30-\mathrm{CH}_{2}$, which can be interpreted as being due to the different configuration at the anomeric center $\mathrm{C}-29$. The presence of a hydrolyzable hemiketal bond at this position 29 is in agreement with the experimental evidence that factors 1 and 3 are in equilibrium when kept in aqueous solvents ${ }^{1)}$. The interpretation of the existence of two anomeric isomers is new for kirromycins and likely refers to the early observation of an equilibrium in solution for kirromycin itself ${ }^{14)}$. This fact was recently interpreted as a possible tautomeric equilibrium ${ }^{11)}$ but the authors do not report any NMR data for the single tautomer or any convincing discussion. A further reasoning is that the most plausible tautomerism may operate at the pyridone ring, but the ${ }^{1} \mathrm{H}$ NMR spectra of SB22484 factors do not show important differences between the signals concerning this moiety of isomers 1 and 3 .

The spectrum of factor 4 differs from that of factor 3 only for the signals at $0.85 \mathrm{ppm}, 46-\mathrm{CH}_{3}(1.10$, $\left.45-\mathrm{CH}_{3}\right), 1.65 \mathrm{ppm}, 45-\mathrm{CH}_{2}$ (absent), and $2.35 \mathrm{ppm}, 28-\mathrm{CH}(2.50,28-\mathrm{CH})$. Consequently, factor 4 must have the same configuration at the chiral center 29 as that of factor 3 . It was not possible to obtain pure 
Table 3. ${ }^{1} \mathrm{H}$ NMR data in DMSO- $d_{6}(\delta, \mathrm{ppm})$ and structural attributions for the couple of factors 1 and 3.

\begin{tabular}{|c|c|c|c|c|c|c|c|c|c|}
\hline \multirow{2}{*}{$\begin{array}{c}\text { Proton } \\
\text { No. }\end{array}$} & \multirow{2}{*}{ PHELF } & \multirow{2}{*}{ KIRRO } & \multicolumn{2}{|c|}{ Factor } & \multirow{2}{*}{$\begin{array}{c}\text { Proton } \\
\text { No. }\end{array}$} & \multirow{2}{*}{ PHELF } & \multirow{2}{*}{ KIRRO } & \multicolumn{2}{|c|}{ Factor } \\
\hline & & & 3 & 1 & & & & 3 & I \\
\hline 39 & 1.75 & 1.74 & 1.69 & 1.71 & $44\left(\mathrm{CH}_{3}\right)$ & 1.65 & 1.68 & 1.61 & 1.61 \\
\hline 38 & 5.50 & 5.44 & 5.42 & 5.42 & 20 & 3.40 & 3.37 & 3.31 & 3.31 \\
\hline 37 & 6.03 & 6.00 & 6.00 & 5.98 & $43\left(\mathrm{OCH}_{3}\right)$ & 3.30 & 3.17 & 3.07 & 3.07 \\
\hline 36 & 6.60 & 6.58 & 6.47 & 6.47 & 19 & 1.70 & 2.19 & 2.09 & 2.07 \\
\hline 35 & 5.68 & 5.67 & 5.61 & 5.58 & $42\left(\mathrm{CH}_{3}\right)$ & 0.72 & 0.84 & 0.76 & 0.76 \\
\hline 33 & 4.31 & 4.23 & 4.48 & 4.45 & 17 & 4.62 & 3.65 & 3.75 & 3.75 \\
\hline 32 & & & 1.80 & 1.75 & 16 & 2.00 & 4.20 & 4.06 & 4.05 \\
\hline $47\left(\mathrm{CH}_{3}\right)$ & $\begin{array}{l}0.94 \\
0.89\end{array}$ & $\begin{array}{l}0.90 \\
0.90\end{array}$ & 0.70 & 0.61 & $\begin{array}{l}16-\mathrm{OH} \\
15\end{array}$ & $\begin{array}{l}\text { n.i. } \\
4.38\end{array}$ & $\begin{array}{l}\text { n.i. } \\
4.30\end{array}$ & $\begin{array}{l}\text { n.i. } \\
4.39\end{array}$ & $\begin{array}{l}\text { n.i. } \\
4.42\end{array}$ \\
\hline 31 & 3.83 & 3.61 & 4.02 & 4.02 & $15-\mathrm{OH}$ & n.i. & n.i. & n.i. & n.i. \\
\hline $31-\mathrm{OH}$ & n.i. & n.i. & n.i. & n.i. & 14 & 4.37 & 4.26 & 4.16 & 4.14 \\
\hline $30\left(\mathrm{CH}_{2}\right)$ & 5.02 & 3.68 & $\begin{array}{l}1.70 \\
1.25\end{array}$ & $\begin{array}{l}1.90 \\
1.43\end{array}$ & $\begin{array}{l}13 \\
12\end{array}$ & $\begin{array}{l}6.12 \\
6.43\end{array}$ & $\begin{array}{l}6.03 \\
6.41\end{array}$ & $\begin{array}{l}6.00 \\
6.34\end{array}$ & $\begin{array}{l}5.97 \\
6.36\end{array}$ \\
\hline $29-\mathrm{OH}$ & n.i. & n.i. & 6.02 & n.i. & 11 & 6.72 & 6.54 & 6.61 & 6.63 \\
\hline 28 & 2.97 & 2.78 & 2.50 & 2.50 & 10 & 6.43 & 6.60 & 6.61 & 6.63 \\
\hline $45\left(\mathrm{CH}_{3}\right)$ & & & 1.10 & 1.06 & 9 & 7.30 & 6.60 & 6.82 & 6.84 \\
\hline $26(\mathrm{NH})$ & n.i. & 7.78 & 8.16 & 7.82 & $41\left(\mathrm{CH}_{3}\right)$ & & 2.00 & 1.88 & 1.86 \\
\hline 25 & $\begin{array}{l}4.02 \\
4.02\end{array}$ & $\begin{array}{l}4.05 \\
3.91\end{array}$ & $\begin{array}{l}3.80 \\
3.80\end{array}$ & $\begin{array}{l}3.75 \\
3.75\end{array}$ & $\begin{array}{l}6 \\
5\end{array}$ & & $\begin{array}{l}7.60 \\
5.97\end{array}$ & $\begin{array}{l}7.28 \\
5.93\end{array}$ & $\begin{array}{l}7.28 \\
5.93\end{array}$ \\
\hline 24 & 5.67 & 5.72 & 5.64 & 5.64 & 4-OH & & n.i. & $11.2 \sim 10.7$ & $11.2 \sim 10.7$ \\
\hline 23 & 6.52 & 6.52 & 6.48 & 6.48 & $40(\mathrm{NH})$ & & n.i. & $11.2 \sim 10.7$ & $11.2 \sim 10.7$ \\
\hline 22 & 5.98 & 6.02 & 5.99 & 5.99 & & & & & \\
\hline
\end{tabular}

PHELF: Phenelfamycin A (data from acetone- $d_{6}$ solution) ${ }^{10)}$.

KIRRO: Kirromycin (data from acetone- $d_{6}$ solution) ${ }^{11)}$.

n.i.: Not identified.

Table 4. Protons involved in dipolar coupling as revealed by the NOESYPH experiment for factor 3.

$47-\mathrm{CH}_{3} \rightarrow 35-\mathrm{H}, \quad 47-\mathrm{CH}_{3} \rightarrow 30-\mathrm{H}, \quad 45-\mathrm{CH}_{3} \rightarrow 29-\mathrm{OH}, 44-\mathrm{CH}_{3} \rightarrow 23-\mathrm{H}, \quad 44-\mathrm{CH}_{3} \rightarrow 43-\mathrm{OCH}_{3}$, $44-\mathrm{CH}_{3} \rightarrow 42-\mathrm{CH}_{3}, \quad 22-\mathrm{H} \rightarrow 20-\mathrm{H}, \quad 20-\mathrm{H} \rightarrow 17-\mathrm{H}_{3} \quad 43-\mathrm{OCH}_{3} \rightarrow 17-\mathrm{H}, \quad 29-\mathrm{OH} \rightarrow 33-\mathrm{H}$

factor 2 suitable for NMR studies because of its low abundance in the complex. However, the LC-MS fragmentation of both factors 2 and 4 are consistent with this structure and also indicate that factor 2 has an ethyl group at position 28. It was also found that the two isomers 2 and 4 easily equilibrate under the same conditions as described for isomers 1 and 3 . Consequently, factors 2 and 4 are very likely isomers at position 29. This is supported by the strong analogy between the two pairs of isomers 1 and 3 , and 2 and 4 , as deduced from the LC-MS fragmentation, from the capacity to equilibrate in solution and from the HPLC retentivity. Consequently, the configuration of the anomeric center C-29 is $S(\alpha)$ for factor 4 and $R(\beta)$ for factor 2.

In conclusion, factor 3 can be described as $N$-[7-[5(R)-[7-[1,2-dihydro-4-hydroxy-1H-2-oxo-3pyridinyl]-6-methyl-7-oxo-1 $(E), 3(E), 5(E)$-heptatrienyl] tetrahydro-3( $S), 4(R)$-dihydroxyfuran-2(S)-yl]$6(S)$-methoxy-5,7(R)-dimethyl-2(E),4(E)-heptadienyl]- $\alpha(S)$-methyl-5(S)-methyltetrahydro-2(S),4(S or $R)$ dihydroxy-6(S)-[1(E),3(Z)-pentadienyl]-2H-pyran-2-acetamide. Factor 1 is isomeric to factor 3 for the opposite configuration at the anomeric center. Factors 2 and 4 have an ethyl group instead of the methyl group $\alpha$ to the acetamide moiety and are in the same relationship as the pair 1 and 3 for the anomeric configuration.

\section{References}

1) Selva, E.; G. Beretta, R. Pallanza, B. P. Goldstein, M. Berti, D. M. F. Edwards \& M. Denaro: Antibiotic SB22484: A novel complex of the aurodox group. I. Taxonomy of the producing organism, isolation of the 
antibiotics and chemical and biological characterization. J. Antibiotics 43: 1349 1358, 1990

2) Parmeggiani, A. \& G. W. M. Swart: Mechanism of action of kirromycin-like antibiotics. Annu. Rev. Microbiol. 39: $557 \sim 577,1985$

3) Parmeggiani, A. \& G. Sander: Part C. Properties and action of kirromycin (mocimycin) and related antibiotics. In Topics in Antibiotic Chemistry. Volume 5. Ed., P. G. SAmmes, pp. $159 \sim 221$, Ellis Horwood Limited, 1980

4) MaEhr, H.; M. Leach, L. YarmchuK \& M. Mitrovic: Antibiotic X-5108. IX. Chemical conversion of mocimycin to aurodox and derivatives of aurodox, goldinamine and mocimycin. J. Antibiotics 32: 361 367, 1979

5) Maehr, H.; M. LeACH, T. H. Williams \& J. F. Blount: The chemistry of aurodox and related antibiotics. Can. J. Chem. 58: $501 \sim 526,1980$

6) Stern, E. S. \& C. J. Timmons (Ed.): Electronic Absorption Spectroscopy in Organic Chemistry. Edward Arnold Publish, 1970

7) Berger, J.; H. H. Lehr, S. Teitel, H. Maehr \& E. Grunberg: A new antibiotic X-5108 of Streptomyces origin. I. Production, isolation and properties. J. Antibiotics 26: 15 22, 1973

8) SCOTt, A. I.: Interpretation of the spectra of natural products. Ed., Pergamon Press, pp. 178 184, Pergamon Press, 1964

9) Edwards, D. M. F.; E. Selva, S. Stella, L. F. Zerilli \& G. G. Gallo: Mass spectrometric techniques for structure and novelty determination of kirromycin-like antibiotics. Biomed. Env. Mass Spectrom., to submitted

10) Hochlowski, J. E.; M. H. Buytendorp, D. N. Whittern, A. M. Buko, R. H. Chen \& J. B. McAlpine: Phenelfamycins, a novel complex of elfamycin-type antibiotics. II. Isolation and structure determination. J. Antibiotics 41: $1300 \sim 1315,1988$

11) Barber, J.; A. E. Derome, T. D. Howard, L. Lian \& G. Tebr: Full assignment of the ${ }^{1} \mathrm{H}$ and ${ }^{13} \mathrm{C}$ NMR spectra of the antibiotic kirromycin (mocimycin). Magn. Reson. Chem. 27: 748 753, 1989

12) A73A. Index of Antibiotics and Other Microbial Products. J. Antibiotics 36: 83-11, 1983

13) A40A. Index of Antibiotics and Other Microbial Products. J. Antibiotics 35: 82-92, 1982

14) Vos, C. \& P. E. J. Verwiel: The total structure of the novel antibiotic mocimycin (MYC 8003). Tetrahedron Lett. 1973: $5173 \sim 5176,1973$ 